\title{
Kinder sind unsere Zukunft!
}

Die dritte Ausgabe der Zeitschrift Sport- und Präventivmedizin beschäftigt sich mit dem Schwerpunktthema „Kinder und Sport“.

Um dem Problem der atraumatischen Todesfälle und kardialen Zwischenfälle im Sport adäquat entgegenzutreten, sowie um andere prädisponierende Faktoren und Krankheiten inklusive Auffälligkeiten am Haltungs- und Bewegungsapparat ausschließen zu können, zeigt sich umso mehr, wie wichtig es ist, sportmedizinische Untersuchungen bereits im Kindesalter durchzuführen.

Kinder sind die Erwachsenen von Morgen und es ist unbestritten und eindeutig erwiesen, dass körperlich aktive Kinder das beste Rüstzeug für ein gesundes Erwachsenwerden bis hin ins hohe Alter besitzen.

Das Altagsleben wird jedoch zusehends von einer eklatanten Bewegungsarmut und einem enormen Leistungsdruck bestimmt, beides Faktoren die den zunächst natürlich vorhandenen Bewegungsdrang der Kinder unterminieren. Die dadurch verursachten, negativen Folgen in Form der klassischen Zivilisationskrankheiten sind jedoch erst zeitverzögert zu beobachten.

Unser aller Anliegen - und damit meinen wir nicht nur Kolleginnen und Kollegen, sondern auch die politischen Entscheidungsträger/innen und insbesondere die Eltern, die gerne ihre diesbezügliche Verantwortung abgeben - muss es sein Kinder zu mehr Bewegung zu motivieren und sie Sport gesund erleben zu lassen.

Es gibt keine vernünftigere Zukunftsvorsorge!

Die aktuelle Ausgabe der Zeitschrift ist Herrn Univ. Prof. Dr. Peter H. Schober, dem Präsidenten der ÖGSMP und einem der Pioniere der Österreichischen Kindersportmedizin, zum 60. Geburtstag gewidmet. Lesen Sie dazu eine Laudatio, die sein visionäres Denken, Tun und Handeln illustriert.

\section{Univ.-Prof. Dr. Norbert Bachl}

Herausgeber

Interessenskonflikt

Es besteht kein Interessenskonflikt.

\section{Dr. Piero Lercher}

Editor in Chief

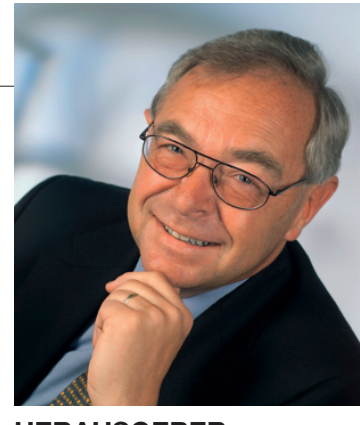

HERAUSGEBER

Univ.-Prof.

Dr. Norbert Bachl

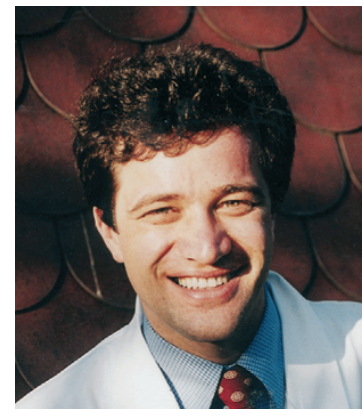

EDITOR IN CHIEF

Dr. Piero Lercher 